\title{
Evaluación ambiental en el escenario actual y con bonos de carbono: páramo La Cortadera, departamento de Boyacá, Colombia
}

\author{
Recepción: 22 de octubre de 2020 - Evaluación: 17 de diciembre de 2021 - Aprobación: 20 de enero de 2022
}

Resumen: Este estudio evaluó las condiciones ambientales y socioeconómicas del páramo La Cortadera con el fin de identificar los impactos ambientales que se deben considerar en la prestación del servicio de captura de carbono. Mediante la metodología de la Secretaría Distrital de Medio Ambiente (2013) para la valoración y evaluación ambiental, se plantearon dos escenarios, el actual y uno con bonos de carbono, con el fin de comparar cómo la prestación del servicio de captura contribuye a la recuperación y la conservación del medio ambiente. Dentro de los resultados, se identificaron 82 impactos en el escenario actual, en donde predominan los adversos significativos, temporales y mitigables relacionados con las actividades antrópicas que se realizan en el páramo; mientras que en el escenario con bonos de carbono se identificaron 30 impactos ambientales asociados a los medios biótico, abiótico y socioeconómico, de los cuales 25 son positivos y se encuentran clasificados mayoritariamente como significativos y de importancia alta, vinculados con actividades de administración del área protegida, institucionalidad, investigación, generación de conocimiento y fortalecimiento del componente socioeconómico y cultural. De acuerdo con los impactos negativos del escenario actual (90\%), el páramo presenta en su lindero un grado de afectación y fragmentación considerable atribuido principalmente a la expansión de la frontera agropecuaria. Por tal motivo, como muestran los resultados en el escenario con bonos de carbono (83\% de impactos positivos), la estructuración de un protocolo para la prestación del servicio de captura en el ecosistema y del plan de manejo ambiental para mitigar los impactos identificados contribuirían a su recuperación, conservación y desarrollo sostenible.

Palabras clave: captura de carbono, evaluación ambiental, impacto ambiental, páramo, suelo de páramo.

Para citar: Vargas Terranova, C. A.., González Diaz, J. M.., \& Rueda Ramírez, M. A. (2022). Evaluación ambiental en el escenario actual y con bonos de carbono: páramo La Cortadera, departamento de Boyacá, Colombia. Perspectiva Geográfica, 27(1), 125-145. https://doi. org/10.19053/01233769.11953

Magíster en Geografía, Universidad Pedagógica y Tecnológica de Colombia. Docente del programa de Ingeniería Ambiental y Sanitaria, Universidad de La Salle, Bogotá, Colombia. Correo: javigonzalez@unisalle.edu.co. Orcid: https://orcid. org/0000-0003-1752-9966 


\title{
Environmental assessment in the current scenario and with carbon credits: La Cortadera moor, department of Boyacá, Colombia
}

\begin{abstract}
This study assessed the environmental and socioeconomic conditions of the La Cortadera moor in order to identify the environmental impacts to be considered in the provision of the carbon capture service. Using the methodology of the Secretaría Distrital de Medio Ambiente (2013) for environmental assessment and evaluation, two scenarios were proposed, the current and one with carbon credits, in order to compare how the provision of the capture service contributes to the recovery and conservation of the environment. Among the results, 82 impacts were identified in the current scenario, where significant, temporary and mitigable adverse impacts related to the anthropic activities carried out in the moor predominate; while in the scenario with carbon credits, 30 environmental impacts associated with the biotic, abiotic and socioeconomic environments were identified, of which 25 are positive and are classified mostly as significant and of high importance, linked to activities of administration of the protected area, institutionalism, research, generation of knowledge and strengthening of the socioeconomic and cultural component. According to the negative impacts of the current scenario (90\%), the moor has been affected and fragmented to a considerable degree, mainly due to the expansion of the agricultural frontier. For this reason, as shown by the results in the scenario with carbon credits (83\% positive impacts), the structuring of a protocol for the provision of the capture service in the ecosystem and the environmental management plan to mitigate the identified impacts would contribute to its recovery, conservation and sustainable development.
\end{abstract}

Keywords: carbon capture, environmental assessment, environmental impact, moor, moorland.

\section{Avaliação ambiental no cenário atual e com títulos de carbono: páramo La Cortadera, Estado de Boyacá, Colômbia}

Resumo: Este estudo avaliou as condições ambientais e socioeconômicas do pântano La Cortadera para identificar os impactos ambientais que devem ser considerados na prestação do serviço de captura de carbono. Através da metodologia da Secretaria Distrital de Meio Ambiente (2013) para a valorização e avaliação ambiental, foram propostos dois cenários, o atual e um com bônus de carbono, a fim de comparar a forma como a prestação do serviço de captura contribui para a recuperação e a conservação do ambiente. Dentro dos resultados, foram identificados 82 impactos no cenário atual, onde predominam os adversos significativos, temporais e mitigados relacionados às atividades antrópicas realizadas no páramo; no entanto que no cenário das emissões de carbono foram identificados 30 impactos ambientais associados ao meio biótico, abiótico e socioeconómico, dos quais 25 são positivos e estão classificados, na sua maioria, como significativos e de elevada importância, ligados a atividades de administração da área protegida, institucionalidade, investigação, geração de conhecimento e fortalecimento do componente socioeconômico e cultural. De acordo com 
os impactos negativos do cenário atual $(90 \%)$, o páramo apresenta em seu limite um grau de afetação e fragmentação considerável atribuído principalmente à expansão da fronteira agropecuária. Por esta razão, como mostram os resultados no cenário com bônus de carbono (83\% impactos positivos), a estruturação de um protocolo para a prestação do serviço de captura no ecossistema e do plano de gestão ambiental para mitigar os impactos identificados contribuiriam para a sua recuperação, conservação e desenvolvimento sustentável.

Palavras-chave: captura de carbono, avaliação ambiental, impacto ambiental, páramo, solo de páramo. 


\section{Introducción}

La evaluación ambiental nace como una herramienta de protección ambiental que, apoyada por la institucionalidad de acuerdo con las necesidades de los distintos países, fortalece la toma de decisiones a nivel de políticas, planes, programas y proyectos (Maza, 2007). La evaluación ambiental también puede ser definida como el mecanismo de gestión más adecuado para prevenir y mitigar los impactos potenciales que las actividades o proyectos puedan generar en el medio (Wood, 2003).

Debido a la importancia de dicha herramienta, en este trabajo se evaluaron las condiciones ambientales del ecosistema de páramo con el fin de comparar su grado de afectación actual versus la implementación de proyectos relacionados con bonos de carbono. Pero ¿por qué estudiar el ecosistema de páramo? La importancia de este ecosistema está directamente relacionada con las funciones fundamentales que proveen para el bienestar social y humano de la población, como la purificación del aire, el almacenamiento de carbono, el abastecimiento de agua y la regulación de la temperatura (Márquez, 2014). Estos ecosistemas son únicos en el mundo y se localizan entre los 3.200 y los 4.500 m. s. n. m. en las cadenas montañosas de los Andes de Colombia, Venezuela, Ecuador, al norte de Perú y en Costa Rica y Panamá (Hernández \& Lizarazo, 2015).

De acuerdo con Rivera y Rodríguez (2011), en el sistema montañoso de los Andes en el territorio colombiano se encuentran ecosistemas de páramo donde nacen las principales estrellas fluviales del país, las cuales abastecen de agua a más del 70\% de los colombianos, almacenan y capturan gas carbónico de la atmósfera, contribuyen en la regulación del clima regional, son hábitat de especies polinizadoras y dispersoras de semillas y son sitios sagrados para la mayoría de culturas ancestrales, entre muchos otros beneficios.

Colombia posee el 49\% del área de páramos en el mundo, la cual ocupa el 1,7\% del territorio nacional
(Greenpeace, 2013). El departamento de Boyacá es el que posee el mayor número de municipios, 19 en total, con una superficie de más del $50 \%$ en los complejos de páramo. Este departamento se encuentra ubicado en la cordillera Oriental de los Andes en Colombia y contiene siete complejos de páramo (Gobernación de Boyacá, 2013).

El Instituto de Investigación de Recursos Biológicos Alexander von Humboldt (2007) indica que el páramo La Cortadera se encuentra ubicado en el departamento de Boyacá, pertenece al complejo Tota-Bijagual-Mamapacha (Figura 1), forma parte de la jurisdicción de los municipios de Toca, Tuta, Siachoque, Rondón y Pesca, y tiene un rango altitudinal de 2.350 a 3.850 m. s. n. m. Es un área protegida del departamento de Boyacá que cuenta con 16.508,41 ha, declarada mediante el acuerdo 024 de 2015 (Corporación Autónoma Regional de Boyacá [Corpoboyacá], 2015), en cuyo ecosistema se conservan muestras representativas de diferentes coberturas vegetales que incluye varios tipos de bosque y páramo (Amar, 2009). Esta zona ha sido clasificada por Corpoboyacá como un área de especial importancia por su elevada recarga y regulación hídrica, que abastece principalmente a las comunidades que habitan los municipios mencionados. Además, es un área importante para la conservación del recurso hídrico por ser fuente de recarga del embalse de La Copa, aporta con sus aguas a ríos como el Pesca, Jordán, Tuta, Salitre y Muche, y forma parte de las cuencas de los ríos Chicamocha y Upía.

Sin embargo, la ocupación de áreas de páramo desde mediados del siglo xx trae consigo un conjunto de lógicas y prácticas con las que las comunidades han logrado subsistir y reproducirse socialmente, pero aumentan progresivamente los problemas ambientales al ocasionar la disminución de las fuentes de agua, cambios en los períodos de lluvia y la erosión del suelo (Álvarez \& Barreto, 2016). La problemática empieza a ser notable en los últimos años, ya que el impacto ejercido por la ocupación humana del territorio 
y el desarrollo de actividades económicas desplaza los límites naturales, lo que a su vez se manifiesta en las transformaciones ejercidas sobre la cobertura vegetal y en el cambio de heterogeneidad de los paisajes del páramo que afectan la fauna y la flora (Cárdenas, 2000).

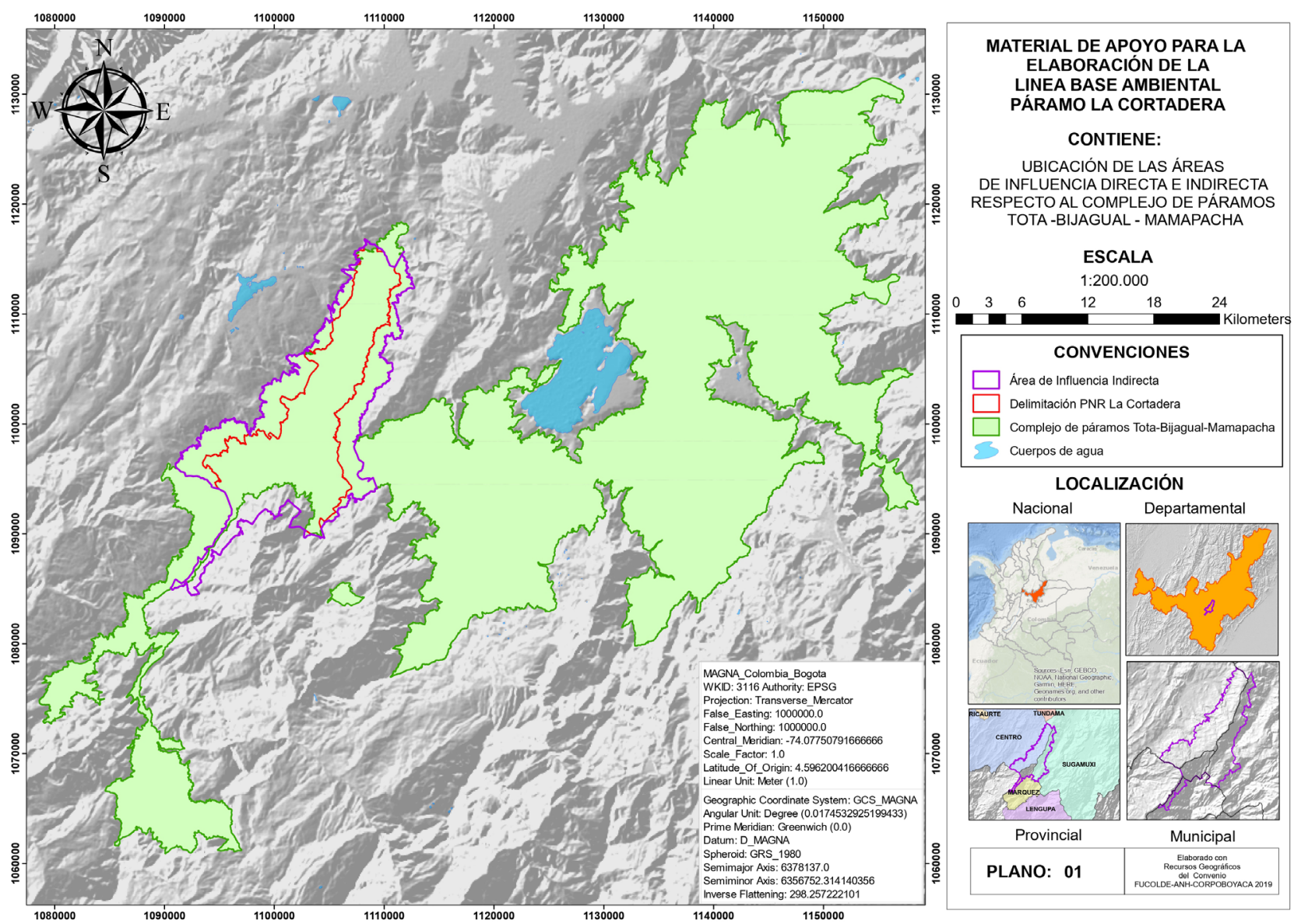

FIGURA 1. Localización del páramo La Cortadera: polígono verde: complejo Tota-Bijagual-

Mamapacha; morado: páramo La Cortadera; rojo: área protegida

FUENTE: elaboración propia (2020).

Adicionalmente, los fenómenos asociados al cambio climático (como el aumento de temperatura, diferentes regímenes de precipitaciones y nubosidad) pueden agravar esta presión y causar mayores impactos tanto en la funcionalidad y estructura del ecosistema como en sus aspectos sociales y culturales (Holdridge, 1982). Durante los últimos años, los ecosistemas de páramo localizados en zonas de alta montaña han presentado una intensiva degradación como resultado de la pérdida parcial o total de la cobertura vegetal, lo cual genera alteración en la regulación hídrica. Esto es una consecuencia de procesos como el cambio climático, la agricultura, la ganadería y la minería (Garavito, 2015).
Por las razones anteriores, es importante fijar la atención en los ecosistemas de páramo ya que, de acuerdo con Africano et al. (2016), estos tienen una gran capacidad de almacenamiento y captura de carbono atmosférico a través de la retención de materia orgánica en los suelos y se consideran como escenarios de mitigación ante el efecto del cambio climático, especialmente mediante la reducción de gases de efecto invernadero como el $\mathrm{CO}_{2}$. Además, su restauración y conservación garantizará que los diferentes servicios ambientales que presta el páramo se mantengan gracias a su función ecosistémica. 
En el presente artículo se implementó la metodología propuesta por la Secretaría Distrital de Medio Ambiente (2013) para la valoración y evaluación de impactos ambientales de la prestación del servicio ambiental de captura de carbono en suelos del páramo La Cortadera con el fin de reconocer, en un escenario actual, su grado intervención, y en uno con bonos de carbono, su recuperación, conservación, desarrollo sostenible y los principales retos y desafios en su implementación.

\section{Materiales y métodos}

\subsection{Delimitación de áreas de influencia}

Inicialmente, para la delimitación de las áreas de influencia directa, indirecta y operativa se definieron las consideraciones técnicas para la identificación de las áreas correspondientes a los medios biótico, abiótico y socioeconómico con el fin de integrar los resultados y delimitarlas. A continuación, se describe el procedimiento correspondiente.

\subsection{2. Área de influencia indirecta}

Para la delimitación del área de influencia indirecta se utilizó el software ArcMap 10.3. Inicialmente se generó una intersección de la delimitación del Parque Natural Regional (PNR) La Cortadera con el complejo de páramos Tota-Bijagual-Mamapacha. A partir del análisis de las coberturas de la tierra de los años 2016 y 2019, se diferenciaron y delimitaron áreas de coberturas naturales e intervenidas ya que, a nivel regional, los resultados de los estudios elaborados por Africano et al. (2016) y Pérez et al. (2018) sobre la aptitud del suelo de páramo para la captura de carbono muestran que el potencial de captura es mayor en coberturas que no han sido intervenidas o se encuentran en recuperación, por lo cual dichas áreas son de interés para definir en dónde la prestación del servicio ambiental tendrá un mayor impacto.

\subsection{3. Área de influencia directa}

De acuerdo con la Autoridad Nacional de Licencias Ambientales (ANLA, 2018), el área de influencia directa de un proyecto, obra o actividad se define como la zona en la cual se manifiestan los impactos ambientales significativos. Con base en la anterior definición, la delimitación del área de influencia directa del proyecto se realizó a partir de la determinación de criterios asociados a los componentes de los medios biótico, abiótico y socioeconómico. En la Tabla 1 se muestran los criterios seleccionados para la prestación del servicio ambiental de captura de carbono.

\begin{tabular}{|c|c|c|}
\hline Medio & Componente & Criterios \\
\hline \multirow{4}{*}{ Abiótico } & \multirow{2}{*}{ Hídrico } & Índice de aridez \\
\hline & & Índice de retención y regulación hídrica \\
\hline & Suelo & Cambio en las coberturas de tierra \\
\hline & Atmosférico & Regulación del clima \\
\hline \multirow{3}{*}{ Biótico } & \multirow{3}{*}{ Ecosistemas } & Biodiversidad de especies - Colapso total \\
\hline & & Biodiversidad de ecosistemas - Coberturas de tierra \\
\hline & & Conectividad de coberturas naturales \\
\hline \multirow{5}{*}{ Socioeconómico } & Demográfico & Viviendas en el PNR La Cortadera \\
\hline & \multirow{3}{*}{ Económico } & Capacidad y uso del suelo \\
\hline & & Índice de uso del agua \\
\hline & & Sistemas productivos \\
\hline & Cultural & Lugares de interés social o cultural \\
\hline
\end{tabular}

FUENTE: elaboración propia (2020). 
Para la delimitación del área de influencia directa también se consideró como criterio de valoración que las áreas definidas para cada medio contaran con la presencia de puntos de muestreo de suelo definidos para la evaluación de la aptitud de captura de carbono. Después, en el software ArcMap 10.3, se realizó una sumatoria de las áreas identificadas con el fin de identificar las que cumplía con todos o la mayoría de los criterios.

\subsection{4. Área de influencia operativa}

El área de influencia operativa se delimitó a partir de la ubicación de 50 puntos de muestreo que se definieron para la evaluación de aptitud de captura de carbono. Con base en la localización de dichos puntos de muestreo, el área operativa se definió a partir de su unión para la construcción de polígonos y la generación de un área de influencia de 200 metros a partir de la herramienta buffer del software ArcMap 10.3. La selección de esta distancia se determinó de acuerdo con la continuidad y el estado natural de las coberturas de tierra.

\subsubsection{Línea base ambiental}

La elaboración de la línea base ambiental se realizó de acuerdo con lo propuesto por la Autoridad Nacional de Licencias Ambientales (ANLA) en el documento $M e^{-}$ todología general para la elaboración y presentación de Estudios Ambientales (2018), en el cual la estructura principal se basa en la caracterización de múltiples componentes pertenecientes a los medios biótico, abiótico y socioeconómico cuyo objetivo es identificar las variables ambientales, económicas y sociales que tienen lugar en el área determinada para la ejecución de las actividades del proyecto.

Los insumos utilizados fueron: información primaria del área de estudio aportada por la Corporación Autónoma de Boyacá (Corpoboyacá); adicionalmente, se consultaron fuentes de información secundaria como artículos científicos sobre la captura de carbono en suelos de páramo, información geográfica del área de estudio (shapefiles de mapas temáticos, consulta de múltiples geoportales), bibliografía especializada, documentos técnicos e informes oficiales.

\subsubsection{Identificación y evaluación de impactos ambientales}

A continuación, en la Tabla 2 se muestra la definición de los criterios correspondientes a la metodología de identificación de aspectos y valoración de impactos ambientales propuesta por la Secretaría Distrital de Ambiente (2013).

\begin{tabular}{|c|c|c|c|c|}
\hline $\begin{array}{l}\text { Criterios de } \\
\text { valoración }\end{array}$ & Significado & \multicolumn{3}{|c|}{ Escala de valor } \\
\hline Tipo de impacto & $\begin{array}{l}\text { Define el sentido del } \\
\text { cambio ambiental pro- } \\
\text { ducido por una determi- } \\
\text { nada acción del proyecto. } \\
\text { Puede ser positivo (+) o } \\
\text { negativo (-), en función } \\
\text { de si mejora o degrada el } \\
\text { ambiente actual o futuro. }\end{array}$ & $\begin{array}{l}(+) \text { mejora la calidad } \\
\text { ambiental del entorno. }\end{array}$ & \multicolumn{2}{|c|}{ (-) deteriora la calidad ambiental del entorno } \\
\hline Alcance & $\begin{array}{l}\text { Se refiere al área de } \\
\text { influencia del impacto en } \\
\text { relación con el entorno } \\
\text { donde se genera. }\end{array}$ & $\begin{array}{l}1 \text { (puntual): } \\
\text { el impacto queda con- } \\
\text { finado dentro del área } \\
\text { donde se genera. }\end{array}$ & $\begin{array}{l}5 \text { (local): trasciende } \\
\text { los límites del área de } \\
\text { influencia. }\end{array}$ & $\begin{array}{l}10 \text { (regional): tiene } \\
\text { consecuencias a nivel } \\
\text { regional o trasciende } \\
\text { los límites del distrito. }\end{array}$ \\
\hline
\end{tabular}




\begin{tabular}{|c|c|c|c|c|}
\hline $\begin{array}{l}\text { Criterios de } \\
\text { valoración }\end{array}$ & Significado & & Escala de valor & \\
\hline Probabilidad & $\begin{array}{l}\text { Se refiere a la posibilidad } \\
\text { de que se dé el impacto } \\
\text { y está relacionada con } \\
\text { la regularidad (normal, } \\
\text { anormal o de emergen- } \\
\text { cia). }\end{array}$ & $\begin{array}{l}1 \text { (baja): existe una posi- } \\
\text { bilidad muy remota de } \\
\text { que suceda. }\end{array}$ & $\begin{array}{l}5 \text { (media): existe una } \\
\text { posibilidad media de } \\
\text { que suceda. }\end{array}$ & $\begin{array}{l}10 \text { (alta): es muy posible } \\
\text { que suceda en cual- } \\
\text { quier momento. }\end{array}$ \\
\hline Duración & $\begin{array}{l}\text { Se refiere al tiempo que } \\
\text { permanecerá el efecto } \\
\text { positivo o negativo del } \\
\text { impacto en el ambien- } \\
\text { te. Existen aspectos } \\
\text { ambientales que por sus } \\
\text { características se valoran } \\
\text { directamente con la nor- } \\
\text { matividad vigente, como } \\
\text { generación de ruido por } \\
\text { fuentes de combustión } \\
\text { externa, por fuentes de } \\
\text { combustión interna y uso } \\
\text { de publicidad exterior } \\
\text { visual. }\end{array}$ & $\begin{array}{l}1 \text { (breve): alteración del } \\
\text { recurso durante un } \\
\text { lapso muy pequeño. }\end{array}$ & $\begin{array}{l}5 \text { (temporal): alteración } \\
\text { del recurso durante un } \\
\text { lapso moderado. }\end{array}$ & $\begin{array}{l}10 \text { (permanente): } \\
\text { alteración del recur- } \\
\text { so permanente en el } \\
\text { tiempo. }\end{array}$ \\
\hline Recuperabilidad & $\begin{array}{l}\text { Se refiere a la posibilidad } \\
\text { de reconstrucción, total } \\
\text { o parcial, del recurso } \\
\text { afectado por el impac- } \\
\text { to. Existen aspectos } \\
\text { ambientales que por sus } \\
\text { características se valoran } \\
\text { directamente con la } \\
\text { normatividad vigente, } \\
\text { vertimientos domésticos } \\
\text { y no domésticos. Para la } \\
\text { generación de residuos } \\
\text { aprovechables, la califica- } \\
\text { ción será de } 10 \text { tanto para } \\
\text { el impacto positivo como } \\
\text { para el negativo. }\end{array}$ & $\begin{array}{l}1 \text { (reversible): puede } \\
\text { eliminarse el efecto por } \\
\text { medio de actividades } \\
\text { humanas tendientes a } \\
\text { restablecer las condi- } \\
\text { ciones originales del } \\
\text { recurso. }\end{array}$ & $\begin{array}{l}5 \text { (recuperable): se pue- } \\
\text { de disminuir el efecto } \\
\text { a través de medidas de } \\
\text { control hasta un están- } \\
\text { dar determinado. }\end{array}$ & $\begin{array}{l}10 \text { (irrecuperable/irre- } \\
\text { versible): el/los recursos } \\
\text { afectados no retor- } \\
\text { nan a las condiciones } \\
\text { originales a través de } \\
\text { ningún medio. } \\
10 \text { (cuando el impacto } \\
\text { es positivo se considera } \\
\text { una importancia alta). }\end{array}$ \\
\hline Cantidad & $\begin{array}{l}\text { Se refiere a la magnitud } \\
\text { del impacto, es decir, la } \\
\text { severidad con la que ocu- } \\
\text { rrirá la afectación o riesgo } \\
\text { sobre el recurso, que } \\
\text { deberá estar relacionada } \\
\text { con la regularidad selec- } \\
\text { cionada. Existen aspectos } \\
\text { ambientales que por sus } \\
\text { características se valoran } \\
\text { directamente con la nor- } \\
\text { matividad vigente, como } \\
\text { la generación de residuos } \\
\text { peligrosos, escombros, } \\
\text { hospitalarios y aceites } \\
\text { usados. }\end{array}$ & $\begin{array}{l}1 \text { (baja): alteración míni- } \\
\text { ma del recurso. Existe } \\
\text { bajo potencial de riesgo } \\
\text { sobre el recurso o el } \\
\text { ambiente. }\end{array}$ & $\begin{array}{l}5 \text { (moderada): altera- } \\
\text { ción moderada del } \\
\text { recurso. Tiene un po- } \\
\text { tencial de riesgo medio } \\
\text { sobre el recurso o el } \\
\text { ambiente. }\end{array}$ & $\begin{array}{l}10 \text { (alta): alteración sig- } \\
\text { nificativa del recurso. } \\
\text { Tiene efectos impor- } \\
\text { tantes sobre el recurso } \\
\text { o el ambiente. }\end{array}$ \\
\hline Normatividad & $\begin{array}{l}\text { Hace referencia a la } \\
\text { normatividad ambiental } \\
\text { aplicable al aspecto o el } \\
\text { impacto ambiental. }\end{array}$ & $\begin{array}{l}\text { 1: no tiene normatividad } \\
\text { relacionada. }\end{array}$ & \multicolumn{2}{|c|}{ 10: tiene normatividad relacionada. } \\
\hline
\end{tabular}

FUENTE: Secretaría Distrital de Ambiente (2013). 
La metodología mencionada permite calcular la importancia del impacto de acuerdo con la Ecuación 1, que resulta en una clasificación entre valores de alta, moderada y baja importancia, de acuerdo con los rangos que se muestran en la Tabla 3.

$$
\mathrm{I}=\mathrm{A} \times \mathrm{P} \times \mathrm{D} \times \mathrm{R} \times \mathrm{C} \times \mathrm{N} \quad(\text { Ecuación } 1)
$$

Donde:

I: Importancia del impacto ambiental
A: Alcance
P: Probabilidad
D: Duración
R: Recuperabilidad
C: Cantidad
$\mathrm{N}$ : Normatividad

$\begin{aligned} & \text { TABLA 3. Rango de importancia según la } \\
& \text { Secretaría Distrital de Ambiente }\end{aligned}$
\begin{tabular}{ll}
\multicolumn{2}{|c|}{ Evaluación cuantitativa y cualitativa } \\
\hline Rango & Descripción \\
\hline $\begin{array}{l}\text { Alta: }>125.000 \text { a } \\
1.000 .000\end{array}$ & $\begin{array}{l}\text { Se deben establecer mecanismos } \\
\text { de mejora, control y seguimiento. }\end{array}$ \\
\hline $\begin{array}{l}\text { Moderada: }>25.000 \text { a } \\
125.000\end{array}$ & $\begin{array}{l}\text { Se debe revisar el control opera- } \\
\text { cional. }\end{array}$ \\
\hline Baja: 1 a 25.000 & $\begin{array}{l}\text { Se debe hacer seguimiento al des- } \\
\text { empeño ambiental. }\end{array}$ \\
\hline
\end{tabular}

FUENTE: Secretaría Distrital de Ambiente (2013).

En lo relacionado con la evaluación cualitativa, la metodología hace referencia a la significancia, la cual permite interpretar de forma unificada la relevancia del impacto ambiental de acuerdo con su valoración y el cumplimiento de la normatividad ambiental aplicable que clasifica los impactos ambientales en significativo y no significativo (ver Tabla 4).

\begin{tabular}{|c|c|}
\hline \multicolumn{2}{|c|}{$\begin{array}{l}\text { TABLA 4. Significancia del impacto } \\
\text { ambiental según la Secretaría Distrital de } \\
\text { Ambiente }\end{array}$} \\
\hline & Evaluación cualitativa \\
\hline Significativo & $\begin{array}{l}\text { Cuando la importancia resulta moderada, } \\
\text { alta o no cumple con la normatividad. }\end{array}$ \\
\hline No significativo & Cuando la importancia es baja. \\
\hline
\end{tabular}

FUENTE: Secretaría Distrital de Ambiente (2013).

\section{Resultados y discusión}

\subsection{Delimitación de áreas de influencia}

\subsection{1. Área de influencia indirecta}

De acuerdo con las consideraciones técnicas, para la identificación de esta área se elaboró la clasificación de las coberturas de la tierra como coberturas naturales e intervenidas, en donde se observó que la mayoría de las áreas de uso intensivo y semiintensivo se encuentran fuera de la delimitación del PNR La Cortadera, pero dentro de la delimitación del área de influencia indirecta. Esta última se definió en función de las variables de precipitación, humedad y temperatura involucradas en la clasificación de zonas de vida de Holdridge, lo que garantiza la continuidad del ecosistema de alta montaña.

\subsection{2. Área de influencia directa}

Los resultados de los criterios definidos para cada medio se integraron a partir de una suma mediante el álgebra de mapas del software de ArcMap 10.3. En las Figuras 2, 3 y 4 se pueden observar en color verde las áreas correspondientes a los medió abiótico, biótico y socioeconómico.

Después de obtener las áreas de cada uno de los medios en software ArcMap 10.3 se realizó una sumatoria de estas y se observó que la delimitación del Parque Natural Regional La Cortadera corresponde al área directa de estudio, ya que allí se cumplen todos los criterios seleccionados al ser integrados. De acuerdo con esto, en la Figura 5 se muestra el área de influencia directa.

\subsection{3. Área de influencia operativa}

De acuerdo con la metodología especificada para la delimitación de las áreas operativas (50 puntos de muestreo con un área de influencia de 200 metros que garantiza la continuidad de cobertura vegetal), en la Figura 5 se observan los resultados correspondientes. 


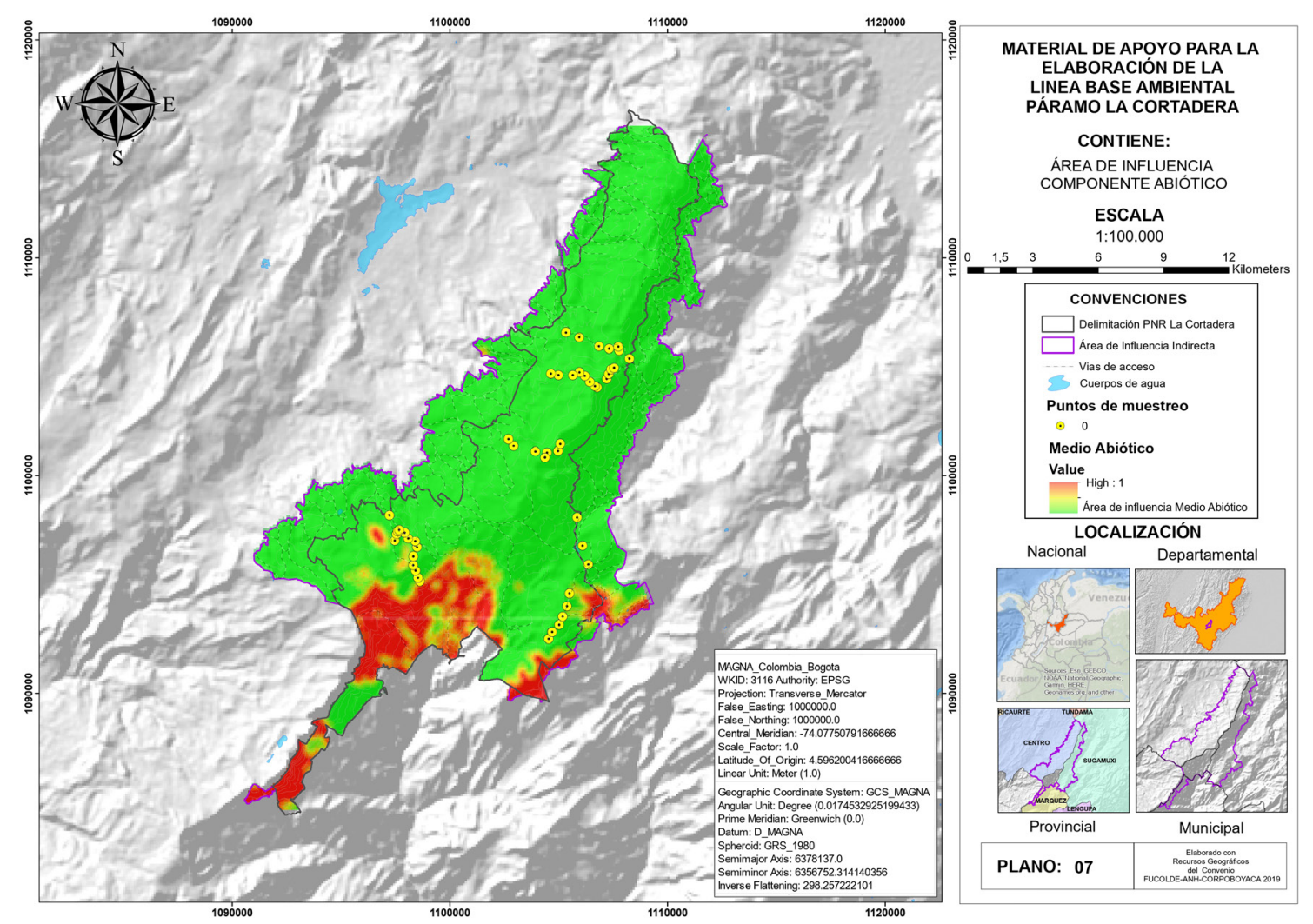

FIGURA 2. Área de influencia: medio abiótico (color verde)

FUENTE: elaboración propia (2020).
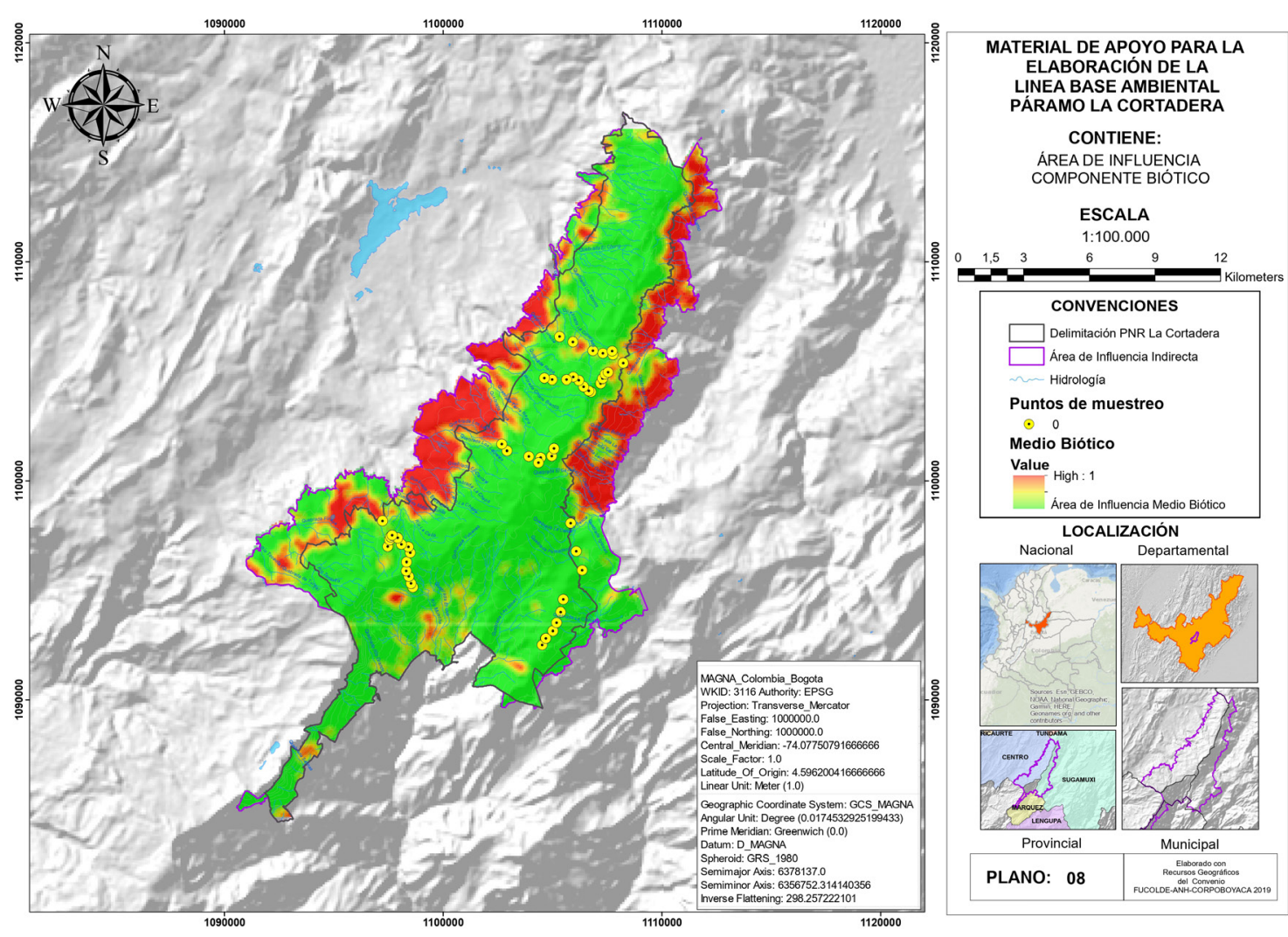

FIGURA 3. Área de influencia: medio biótico (color verde)

FUENTE: elaboración propia (2020). 

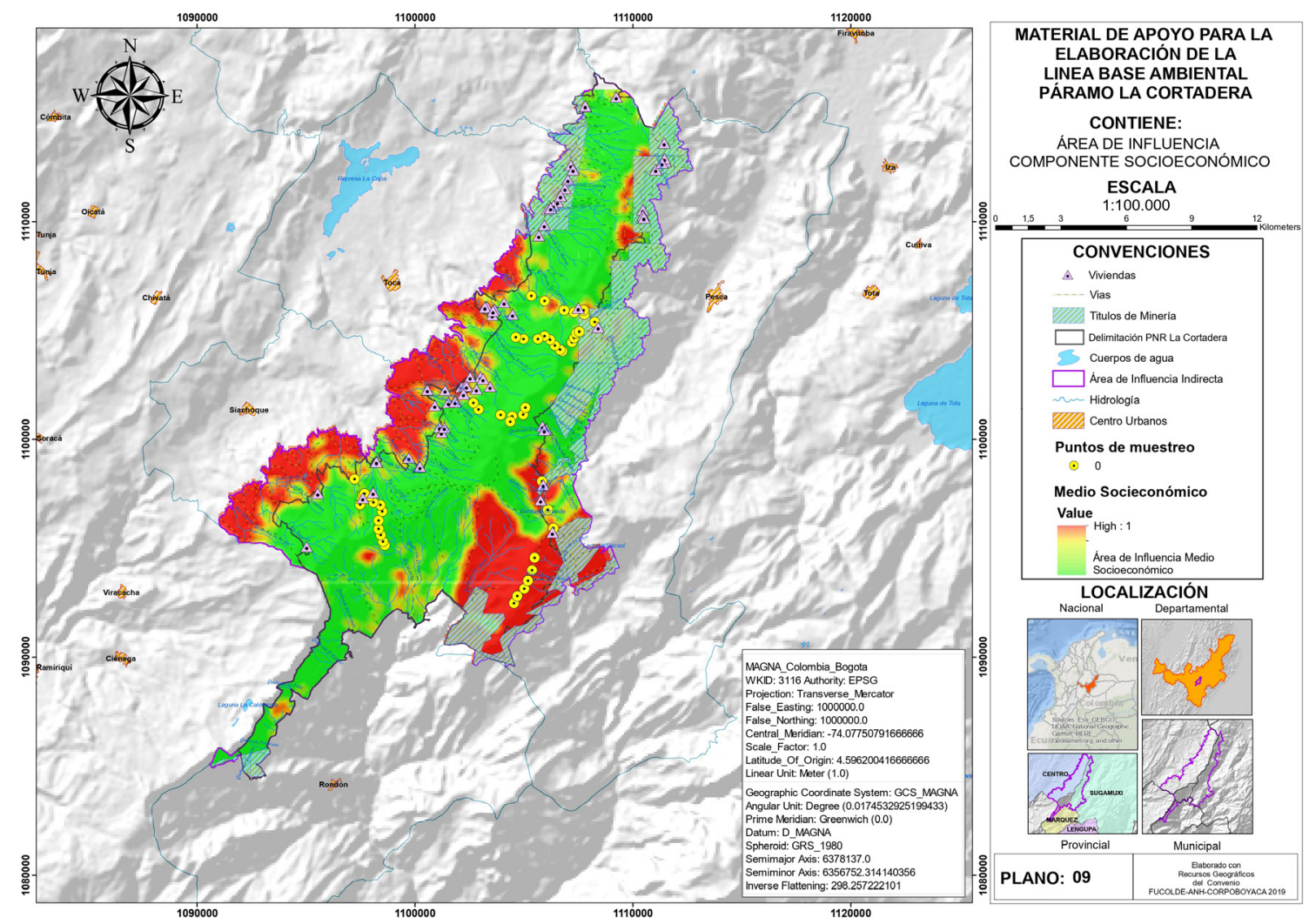

FIGURA 4. Área de influencia: medio socioeconómico (color verde) FUENTE: elaboración propia (2020).

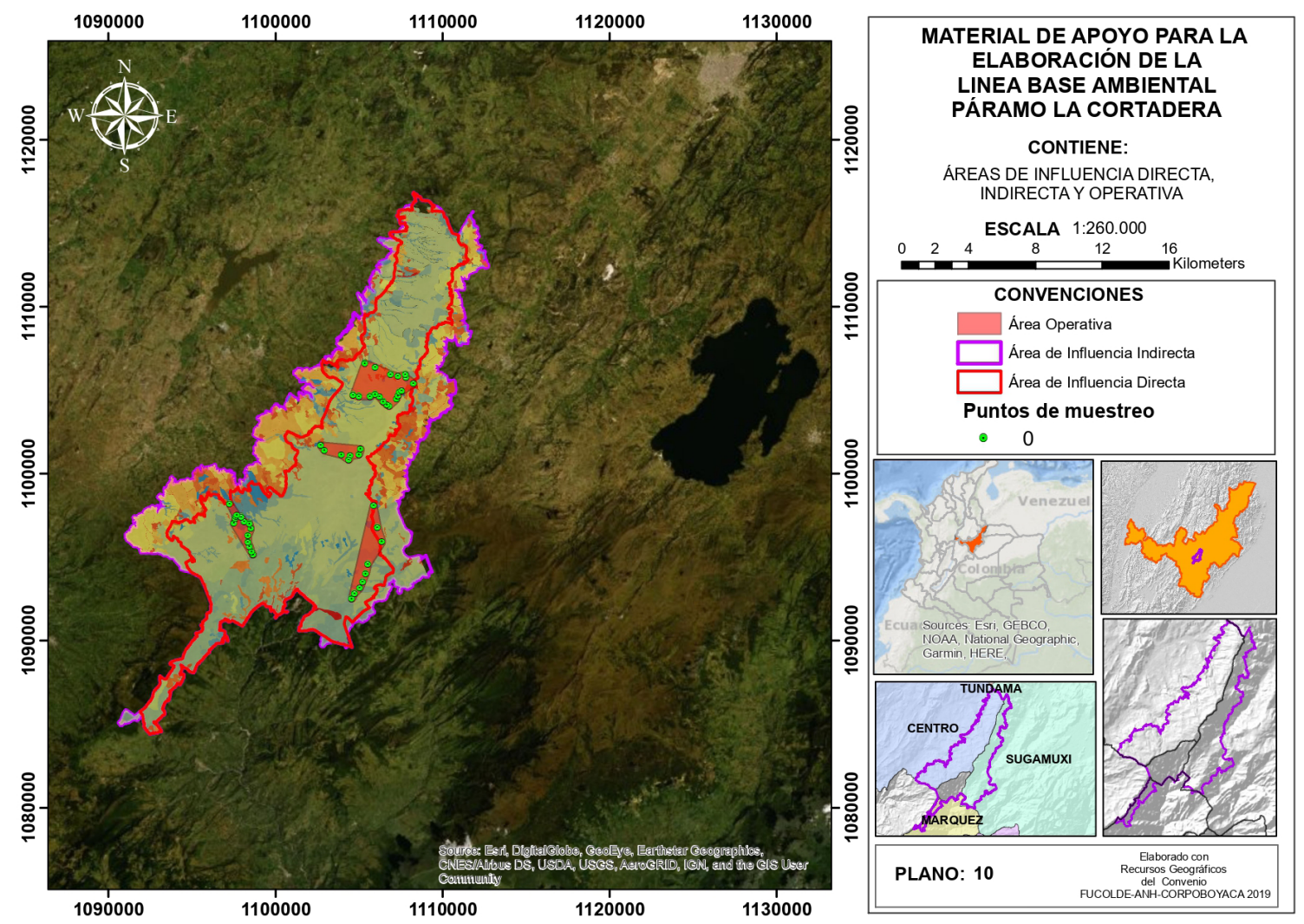

FIGURA 5. Áreas de influencia directa, indirecta y operativa, PNR La Cortadera FUENTE: elaboración propia (2020). 


\subsection{Línea base ambiental}

Los resultados de la línea base ambiental corresponden a la caracterización de los medios biótico, abiótico y socioeconómico del área de estudio. Debido a su extensión, no se relacionan en el presente artículo, sin embargo, fueron el insumo para la identificación y evaluación de impactos ambientales principalmente en el escenario actual.

\subsection{Identificación y evaluación de impactos ambientales}

\subsubsection{Escenario actual}

En la Tabla 5 se presentan los componentes e impactos ambientales identificados para el área de estudio en el escenario actual con el fin de estimar el estado del ecosistema natural del páramo de La Cortadera, mientras que en la Tabla 6 se observa el resumen correspondiente a la evaluación respectiva.

\begin{tabular}{|c|c|c|}
\hline Medio & Componente & Impacto \\
\hline \multirow{26}{*}{ 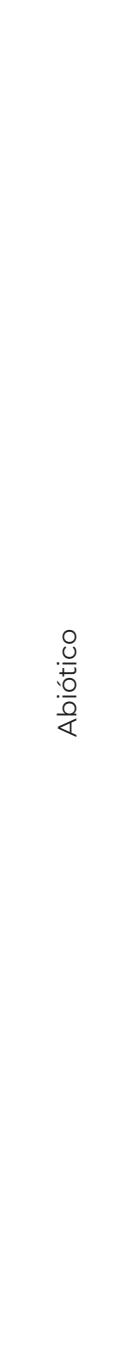 } & \multirow{5}{*}{ Geológico } & Cambio en la susceptibilidad a la erosión. \\
\hline & & Aumento en la inestabilidad del terreno. \\
\hline & & Pérdida de humedad en el suelo. \\
\hline & & Agotamiento de nacimientos de agua. \\
\hline & & Daños en infraestructura por inestabilidad del terreno. \\
\hline & \multirow{3}{*}{ Geomorfológico } & Alteración de las geoformas del terreno. \\
\hline & & Inestabilidad del terreno. \\
\hline & & Movimientos en masa. \\
\hline & \multirow{14}{*}{ Suelos } & Pérdida de coberturas vegetales. \\
\hline & & Cambio en el uso actual del suelo. \\
\hline & & Cambio en la capacidad productiva del suelo. \\
\hline & & Modificación en la capa orgánica del suelo. \\
\hline & & Cambio en las propiedades fisicoquímicas del suelo. \\
\hline & & Compactación del suelo. \\
\hline & & Liberación de $\mathrm{CO}_{2}$ capturado por el suelo. \\
\hline & & Disminución de la materia orgánica del suelo (MOS). \\
\hline & & Pérdida del suelo. \\
\hline & & Pérdida de coberturas vegetales. \\
\hline & & Incremento de la presión antrópica sobre el suelo. \\
\hline & & Pérdida de la capacidad de fijación de dióxido de carbono. \\
\hline & & Cambios en la temperatura superficial del suelo. \\
\hline & & Erosión del suelo. \\
\hline & \multirow{4}{*}{ Hidrológico } & Deterioro de la calidad del agua. \\
\hline & & Alta fragilidad y susceptibilidad ante la intervención antrópica. \\
\hline & & Disminución de los caudales por el mal uso del recurso. \\
\hline & & Presión sobre el recurso hídrico. \\
\hline
\end{tabular}




\begin{tabular}{|c|c|c|}
\hline Medio & Componente & Impacto \\
\hline \multirow{16}{*}{$\frac{8}{\frac{0}{0}}$} & \multirow{4}{*}{ Hidrológico } & Contaminación de agua superficial. \\
\hline & & Riesgo de eutrofización de fuentes de agua. \\
\hline & & Alteración de patrones de drenaje. \\
\hline & & Afectación en la regulación hídrica del páramo. \\
\hline & \multirow{2}{*}{ Hidrogeológico } & Contaminación de agua subterránea. \\
\hline & & Disminución de la capacidad de infiltración y retención de agua. \\
\hline & \multirow{7}{*}{ Paisaje } & Cambio del paisaje en su cobertura vegetal. \\
\hline & & Pérdida de la calidad visual del paisaje. \\
\hline & & Transformación de coberturas. \\
\hline & & Pérdida de cobertura vegetal nativa. \\
\hline & & Disminución del área total del páramo. \\
\hline & & Alteración del paisaje (disminución de la calidad ambiental y visual). \\
\hline & & Pérdida y contaminación de las unidades del paisaje. \\
\hline & \multirow{3}{*}{ Atmosférico } & Cambios en la precipitación y los períodos climáticos. \\
\hline & & Contaminación atmosférica. \\
\hline & & Cambios en la contribución a los gases de efecto invernadero (GEI). \\
\hline \multirow{8}{*}{$\frac{.0}{: 0}$} & \multirow{8}{*}{ Ecosistemas } & Cambio en procesos ecológicos del ecosistema de páramo. \\
\hline & & Especies de flora y fauna endémicas o amenazadas. \\
\hline & & Aseguramiento de la biodiversidad de los ecosistemas. \\
\hline & & Pérdida de biodiversidad característica del ecosistema. \\
\hline & & Modificación del hábitat de las especies. \\
\hline & & Pérdida de la función ecológica del ecosistema. \\
\hline & & Pérdida de especies vegetales nativas. \\
\hline & & Destrucción de hábitats. \\
\hline \multirow{16}{*}{ 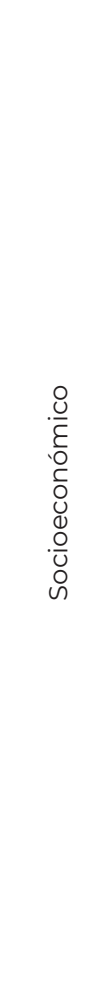 } & \multirow{6}{*}{ Demográfico } & Incremento en las enfermedades. \\
\hline & & Cambio en las dinámicas poblacionales. \\
\hline & & Cambios en la intervención a nivel local del ecosistema para su protección. \\
\hline & & Afectación de las condiciones de salud de la población. \\
\hline & & Aumento de las infecciones respiratorias agudas. \\
\hline & & Intoxicaciones accidentales. \\
\hline & \multirow{2}{*}{$\begin{array}{l}\text { Espacial (información municipal y } \\
\text { local acerca de servicios públicos } \\
\text { y sociales) }\end{array}$} & Cambio en la accesibilidad a los municipios. \\
\hline & & Conflictos de uso por la disponibilidad del recurso hídrico. \\
\hline & \multirow{6}{*}{ Económico } & Cambio en la oferta y demanda de bienes o servicios locales. \\
\hline & & Cambio en el valor del suelo. \\
\hline & & $\begin{array}{l}\text { Prestación de servicios ambientales para el desarrollo sostenible de la } \\
\text { población. }\end{array}$ \\
\hline & & Desarrollo económico ilegal. \\
\hline & & Desarrollo económico de la población. \\
\hline & & Optimización de la salida de carbón para su comercialización. \\
\hline & Cultural & $\begin{array}{l}\text { Permanencia de malas prácticas generacionales en el ecosistema de pára- } \\
\text { mo. }\end{array}$ \\
\hline & Político-organizativo & Tensión social entre actores del páramo (tenencia de tierras). \\
\hline
\end{tabular}

FUENTE: elaboración propia, 2020. 


\begin{tabular}{|c|c|c|}
\hline Ítem & Descripción & Resultados \\
\hline Aspectos & Número de aspectos & 72 \\
\hline Acciones & Número de acciones & 59 \\
\hline Impactos & Número de impactos identificados & 82 \\
\hline \multirow{2}{*}{ Tipo de impacto } & Número de impactos positivos & 8 \\
\hline & Número de impactos negativos & 74 \\
\hline Ítem & Descripción & $\mathrm{N}^{\circ}$ de impactos \\
\hline \multirow{3}{*}{$\begin{array}{l}\text { Importancia ambiental } \\
\text { La clasificación de la importancia ambiental se realizó con base en } \\
\text { la calificación cualitativa y cuantitativa, ya fuera del aspecto o del } \\
\text { impacto ambiental. En este caso, se eligió siempre el escenario más } \\
\text { exigente. }\end{array}$} & Baja & 55 \\
\hline & Moderada & 24 \\
\hline & Alta & 3 \\
\hline \multirow{2}{*}{$\begin{array}{l}\text { Significancia ambiental } \\
\text { Es importante destacar que, en la evaluación ambiental, los aspectos } \\
\text { o impactos ambientales que no cumplían con el marco normativo } \\
\text { nacional, regional o local obtuvieron una calificación baja en el rango } \\
\text { de importancia, pero una significancia ambiental significativa. }\end{array}$} & Significativo & 54 \\
\hline & No significativo & 28 \\
\hline
\end{tabular}

FUENTE: elaboración propia (2020).

Es importante aclarar que los impactos ambientales registrados en la Tabla 5 están directamente relacionados con la definición de las acciones identificadas en el área de estudio a partir de la línea base, las cuales causan una alteración en el ecosistema de páramo que se manifiesta en impactos ambientales en el área de interés.

En este apartado se presenta el análisis de los resultados obtenidos en la matriz del escenario actual, en donde se justifica su valoración y se relaciona con la caracterización ambiental del área de estudio con el fin de comprender la transformación que se ha observado en el ecosistema y cómo se relaciona con los aspectos e impactos ambientales identificados.

Inicialmente, se observó que el páramo de La Cortadera presenta múltiples problemáticas ambientales relacionadas con la ampliación de la frontera agrícola, pérdida de la cobertura vegetal, incremento de la población en la zona de páramo, caza indiscriminada, incendios, contaminación de quebradas, fragmentación del ecosistema, subdivisión predial para asentamientos en zonas de páramo y agricultura (papa, ganadería, haba y zanahoria) en zonas de páramo (Bocarejo et al., 2014).

A continuación, se muestran los resultados obtenidos en la Tabla 6, correspondiente a la metodología de identificación de aspectos y valoración de impactos de la Secretaría Distrital de Ambiente (2013), en donde se realizaron un total de 82 calificaciones entre aspectos e impactos ambientales a partir de la información primaria y secundaria del área de interés para el escenario actual. Es importante aclarar que en este escenario algunas acciones contribuyen al mismo impacto ambiental.

En lo relacionado con el criterio de calificación denominado "tipo de impacto", el cual se califica como positivo (+) o negativo (-) de acuerdo con los efectos de la acción en el ecosistema, se obtuvieron 74 impactos negativos y 8 impactos positivos que explican los cambios que se han observado en el páramo de La Cortadera a través de los años. En la Figura 6 se registran los porcentajes correspondientes para cada tipo de impacto. 


\section{TIPO DE IMPACTO}

- Impactos Positivos $\square$ Impactos Negativos

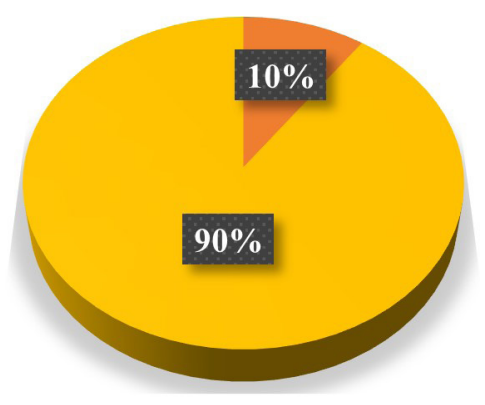

FIGURA 6. Resultados del criterio de calificación "tipo de impacto"

FUENTE: elaboración propia (2020).

En lo que se refiere a la valoración de los criterios de alcance, probabilidad, duración, recuperabilidad, cantidad y normatividad, la calificación se realizó de acuerdo con las condiciones establecidas en la metodología de la Secretaría Distrital de Ambiente (2013). Sin embargo, se debe mencionar que algunas de las calificaciones propuestas por esta entidad son ambiguas respecto al establecimiento de límites relacionados con áreas, tiempo de manifestación del impacto ambiental, duración del impacto, tiempo de recuperabilidad e identificación de la alteración del recurso, por lo tanto, con el apoyo de la metodología de evaluación ambiental propuesta por Conesa (1993), se establecieron rangos de calificaciones con el fin de evaluar cuantitativamente los impactos ambientales identificados. Además, con base en el diagnóstico de actividades, se determinó que el suelo es uno de los recursos más afectados en el páramo de La Cortadera y es por esto por lo que la valoración también está sujeta a la función ambiental del suelo establecida por la revisión de la ecología de los ecosistemas colombianos y el sistema de clasificación de zonas de vida de Holdridge, un esquema para la clasificación de las diferentes áreas terrestres según su comportamiento global bioclimático. Los resultados obtenidos para el rango de importancia se muestran en la Figura 7.

\section{RANGO DE IMPORTANCIA}

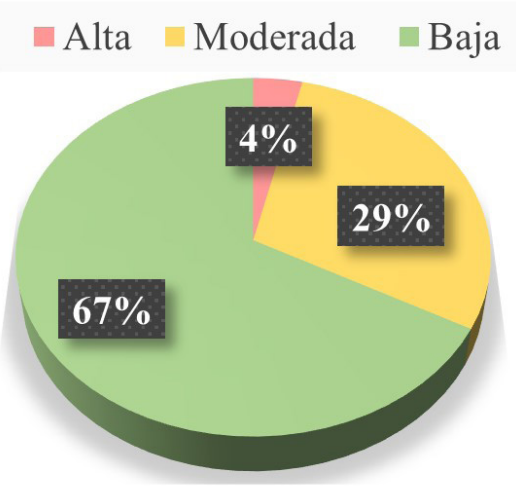

FIGURA 7. Resultados del rango de importancia de los impactos ambientales FUENTE: elaboración propia (2020).

Como se observa en la Figura 7, el mayor porcentaje corresponde al rango de importancia baja, seguido de la importancia moderada y por último la importancia alta. Es clave aclarar que la importancia alta resultó corresponder a diferentes impactos ambientales en cada uno de los medios biótico, abiótico y socioeconómico y que dichos impactos están asociados a la misma acción correspondiente al alinderamiento y zonificación del páramo La Cortadera, lo que quiere decir que la declaratoria como área protegida del páramo y la implementación de proyectos como la prestación del servicio ambiental de captura de carbono permitirán el cambio de la presión antrópica sobre los recursos, el aseguramiento de la biodiversidad de los ecosistemas y asegurará la continuación de la prestación de servicios ambientales para el desarrollo sostenible de la población.

Por último, en la evaluación cualitativa correspondiente a la significancia del impacto ambiental se realizó la identificación de la normatividad aplicable a las acciones relevantes en el área de estudio. Para su valoración también se consideró que si el aspecto o impacto ambiental no contaba con normatividad, su valoración sería significativo. Esto con base en la alteración que se está causando en el ecosistema de 
páramo. Otro factor que se consideró estuvo relacionado con el incumplimiento de la normatividad, el cual también obtuvo una calificación de significativo. De acuerdo con lo anterior, en la Figura 8 se pueden observar los resultados obtenidos para la significancia del impacto ambiental.

\section{SIGNIFICANCIA}

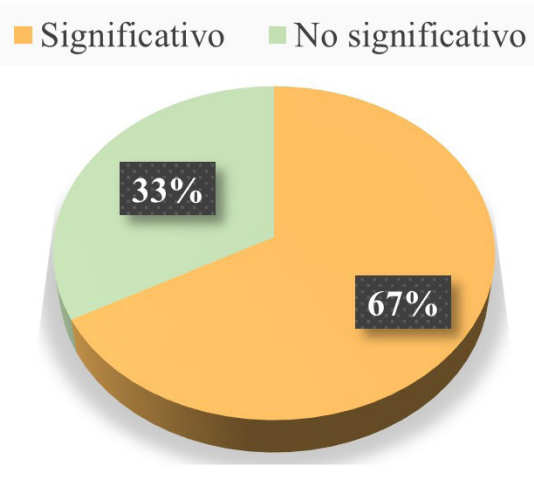

FIGURA 8. Resultados de la significancia de los impactos ambientales

FUENTE: elaboración propia (2020).

Como se observa en la Figura 8, el mayor porcentaje corresponde a la calificación de significativo. Es importante aclarar que aunque el impacto tenga un rango de importancia bajo, resulta significativo por el alcance del impacto o por la falta o incumplimiento de la normatividad ambiental, ya que generalmente se cumple en su mayoría en las área de centros poblados de los municipios de Tuta, Pesca, Toca, Siachoque y Rondón, pero se descuida la vigilancia ambiental en zonas rurales, lo cual causa la afectación del ecosistema de páramo, principalmente por acciones como la expansión de la frontera agrícola, monocultivos, cambio de coberturas vegetales nativas, malas prácticas en actividades agropecuarias y licenciamiento para la actividad de minería, entre otros factores que afectan la función ambiental de recursos como el suelo, en este caso, de gran importancia para la prestación del servicio ambiental de captura de carbono.

\subsubsection{Escenario con bonos de carbono}

En el escenario con bonos de carbono se identificaron los medios y los componentes ambientales susceptibles de recibir impactos en los medios abiótico, biótico y socioeconómico. En la Tabla 7 se presentan los componentes e impactos ambientales identificados con el fin de estimar el estado del ecosistema natural al implementar como estrategia de desarrollo sostenible el esquema de pago por servicio ambiental de captura de carbono en el suelo del páramo La Cortadera.

\begin{tabular}{|c|c|c|}
\hline Medio & Componente & Impacto \\
\hline \multirow{9}{*}{$\begin{array}{l}0 \\
\frac{U}{7} \\
\frac{0}{0} \\
\frac{0}{4}\end{array}$} & \multirow{5}{*}{ Suelos } & Cambio en la calidad y la fertilidad de los suelos. \\
\hline & & Resistencia a la erosión hídrica y eólica. \\
\hline & & Mejoramiento de la capacidad de resiliencia del recurso. \\
\hline & & Disminución de la degradación del suelo. \\
\hline & & Reducción de los conflictos de uso del suelo en áreas de páramo. \\
\hline & Hidrológico & Disminución de la escorrentía de los contaminantes. \\
\hline & Hidrogeológico & Modificación de la distribución de la precipitación entre escorrentía e infiltración. \\
\hline & Paisaje & Disminución de las tasas de deforestación y degradación. \\
\hline & Atmosférico & Disminución de la concentración de $\mathrm{CO}_{2}$ atmosférico. \\
\hline
\end{tabular}




\begin{tabular}{|c|c|c|}
\hline Medio & Componente & Impacto \\
\hline \multirow{4}{*}{ 品 } & \multirow{4}{*}{ Ecosistemas } & Reducción del impacto por alteraciones naturales y antrópicas. \\
\hline & & Fortalecimiento de la biodiversidad del suelo. \\
\hline & & Preservación y restauración del ecosistema. \\
\hline & & $\begin{array}{l}\text { Dificultad de la medición de variabilidad del área determinada para la prestación del servicio } \\
\text { ambiental de captura de carbono (páramo - ecosistema no lineal). }\end{array}$ \\
\hline \multirow{15}{*}{ 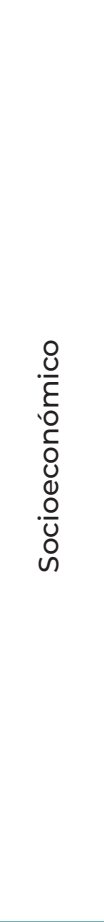 } & \multirow[b]{2}{*}{ Demográfico } & Aumento de modelos más sostenibles que dependen de menos recursos e insumos externos. \\
\hline & & $\begin{array}{l}\text { Aumento en la participación de actores en los esquemas de prestación del servicio ambiental } \\
\text { de captura de carbono. }\end{array}$ \\
\hline & \multirow{7}{*}{ Económico } & Desarrollo económico sostenible bajo el esquema de pagos por servicios ambientales (PSA). \\
\hline & & Alta carga financiera en los esquemas de pagos por servicios ambientales. \\
\hline & & Vinculación de actores del páramo a esquemas de pagos por servicios ambientales (PSA). \\
\hline & & Dificultad en la valoración económica del servicio ambiental. \\
\hline & & Pérdidas en la financiación del servicio ambiental de captura de carbono. \\
\hline & & Desarrollo económico sostenible de la población. \\
\hline & & Estandarización del esquema para la prestación del servicio de captura de carbono. \\
\hline & Cultural & $\begin{array}{l}\text { Mayor apoyo y participación de la comunidad en el esquema del servicio ambiental de captura } \\
\text { de carbono. }\end{array}$ \\
\hline & \multirow{5}{*}{$\begin{array}{l}\text { Político-organi- } \\
\text { zativo }\end{array}$} & $\begin{array}{l}\text { Dificultad para la estructuración de proyectos bajo el esquema de pagos por servicios ambien- } \\
\text { tales. }\end{array}$ \\
\hline & & Cambios en los mecanismos de regulación para la conservación del páramo. \\
\hline & & Aumento de información técnica para la toma de decisiones. \\
\hline & & Fortalecimiento de la aplicación de instrumentos ambientales. \\
\hline & & Mejoramiento del esquema de pago por servicios ambientales. \\
\hline
\end{tabular}

FUENTE: elaboración propia (2020).

Los impactos ambientales consignados en la Tabla 7 se identificaron con base en las acciones por desarrollar en el proceso de vinculación del páramo La Cortadera a un esquema de pago por servicio ambiental de captura de carbono en el suelo. De acuerdo con lo anterior, la identificación de acciones, aspectos e impactos ambientales elaborada para el escenario con bonos de carbono se basó en las actividades de la implementación de dichos esquemas y los efectos que podría generar en el ecosistema de páramo en los medios abiótico, biótico y socioeconómico. A continuación, en la Tabla 8 se presenta el resumen sobre la cantidad de aspectos e impactos positivos y negativos que se identificaron en el área de estudio y también se suministra información sobre la calificación obtenida de la importancia y la significancia de los impactos ambientales que se manifestarían en el área de estudio al prestar el servicio ambiental de captura de carbono.

\begin{tabular}{|lll|}
\hline \multicolumn{2}{|c|}{ TABLA 8. Resumen de la evaluación ambiental para el escenario con bonos de carbono } \\
\hline Aspectos & \multicolumn{1}{c|}{ Descripción } & Resultados \\
\hline Acciones & Número de aspectos & 28 \\
\hline Impactos & Número de acciones & 19 \\
\hline \multirow{2}{*}{ Tipo de impacto } & Número de impactos identificados & 30 \\
\hline
\end{tabular}




\begin{tabular}{|c|c|c|}
\hline Ítem & Descripción & $\mathrm{N}^{\circ}$ de impactos \\
\hline \multirow{3}{*}{$\begin{array}{l}\text { Importancia ambiental } \\
\text { La clasificación de la importancia am- } \\
\text { biental se realizó con base en la califica- } \\
\text { ción cualitativa y cuantitativa, ya fuera } \\
\text { del aspecto o del impacto ambiental; en } \\
\text { este caso, se eligió siempre el escenario } \\
\text { más exigente. }\end{array}$} & Baja & 20 \\
\hline & Moderada & 6 \\
\hline & Alta & 4 \\
\hline \multirow{2}{*}{$\begin{array}{l}\text { Significancia ambiental } \\
\text { Es importante destacar que, en la eva- } \\
\text { luación ambiental, los aspectos o impac- } \\
\text { tos ambientales que no cumplían con } \\
\text { el marco normativo nacional, regional } \\
\text { o local obtuvieron una calificación baja } \\
\text { en el rango de importancia, pero una } \\
\text { significancia ambiental significativa. }\end{array}$} & Significativo & 26 \\
\hline & No significativo & 4 \\
\hline
\end{tabular}

FUENTE: elaboración propia (2020).

De acuerdo con los resultados registrados en la Tabla 8, se construyó la Figura 9 que corresponde al tipo de impacto.

\section{TIPO DE IMPACTO}

- Impactos Positivos $\quad$ Impactos Negativos

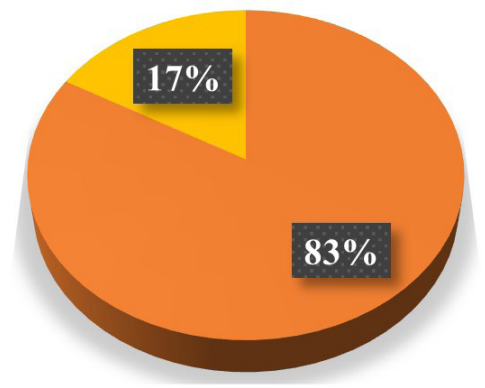

FIGURA 9. Resultados del criterio de calificación "tipo de impacto" FUENTE: elaboración propia (2020).

En la Figura 9 se observa que la evaluación ambiental del criterio "tipo de impacto" elaborada para los medios biótico, abiótico y socioeconómico resultó ser mayoritariamente positiva, lo que quiere decir que el páramo de La Cortadera, visto como escenario de captura de carbono, aportaría al mejoramiento de la función ambiental global del ecosistema y, por tanto, a la prestación de más servicios ecosistémicos de regulación, provisión y culturales.

Por otro parte, en relación con los resultados de los impactos negativos, estos se encuentran principalmente asociados a la dificultad de la estructuración de proyectos bajo el esquema de pago por servicio ambiental, ya que el páramo es considerado como un ecosistema no lineal y por lo tanto cuenta con múltiples variables que influyen directamente en su función ambiental y en la cuantificación y certificación de captura de carbono en las áreas determinadas, lo cual requiere un monitoreo riguroso y una comprensión integrada de los cambios que ocurren en este tipo de ecosistemas.

Adicionalmente, dentro de los impactos negativos, se reconocieron: la dificultad en la identificación de beneficiarios, los altos costos para la evaluación de cambios en el uso del suelo, la dificultad en la medición de variabilidad del área determinada para la prestación del servicio ambiental de captura de carbono y las altas cargas financieras en la estructuración de esquemas de pago por servicio ambiental. En relación con lo anterior, de acuerdo con Andrade (2013), es importante mencionar que los páramos son muy vulnerables al desequilibrio ecológico provocado por factores humanos y naturales y al mismo tiempo están entre las zonas más sensibles a los cambios climáticos de la atmósfera, por esta razón es indispensable contar con información específica sobre la ecología, el estado de conservación o degradación de los ecosistemas, el potencial de los recursos naturales presentes, las actividades socioeconómicas que allí se realizan y el impacto 
que ocasionan, así como su vulnerabilidad al cambio climático (Ministerio del Medio Ambiente, 2002).

De acuerdo con lo anterior, el manejo adecuado de los impactos ambientales negativos que se manifestarían en el páramo de La Cortadera es de gran importancia, ya que sin manejo estos se pueden potencializar y ser vistos como desafios a la hora de realizar la valoración económica, jurídica y ambiental del servicio de captura de carbono. Sin embargo, contar con la línea base ambiental y la zonificación del escenario actual y con bonos de carbono permitirá observar los cambios que ha sufrido el ecosistema y comprender e integrar las variables necesarias para la prestación del servicio ambiental.

Continuando con los resultados de la evaluación ambiental, en la Figura 10 se muestran los porcentajes correspondientes al rango de importancia, en donde se puede observar que el mayor porcentaje pertenece a una importancia baja, seguido de la importancia moderada y por último la importancia alta.

\section{RANGO DE IMPORTANCIA}

- Alta Moderada Baja

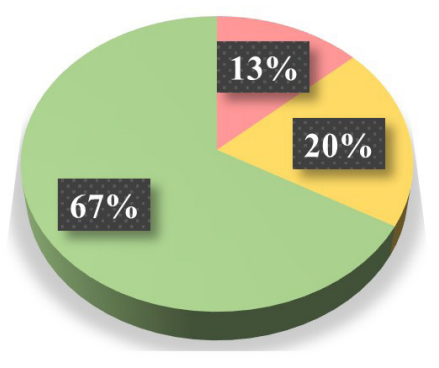

FIGURA 10. Resultados del criterio de

calificación "rango de importancia"

FUENTE: elaboración propia (2020).

Los resultados del criterio de calificación "rango de importancia" permiten identificar los impactos que requieren mayor atención y un especial manejo en un escenario con bonos de carbono. En este caso, se observó que debido a que la mayoría de los impactos ambientales son positivos su rango de importancia es mayoritariamente baja. Dentro de los impactos que presentan un rango de importancia alta se encuentran: la carga financiera en la formulación de un esquema de pago por servicio ambiental, los cambios en los mecanismos de regulación para la conservación del páramo y el aumento de información técnica para la toma de decisiones. Estos impactos están asociados principalmente al componente político-organizativo del medio socioeconómico debido a que el proyecto requiere una buena estructuración de las entidades que están a cargo del páramo de La Cortadera para el desarrollo de estrategias que se concentren en la recuperación del ecosistema estratégico. En la Figura 11 se muestran los resultados correspondientes al criterio de calificación de la significancia.

\section{SIGNIFICANCIA}

$\square$ Significativo $\square$ No Significativo

\section{$13 \%$}

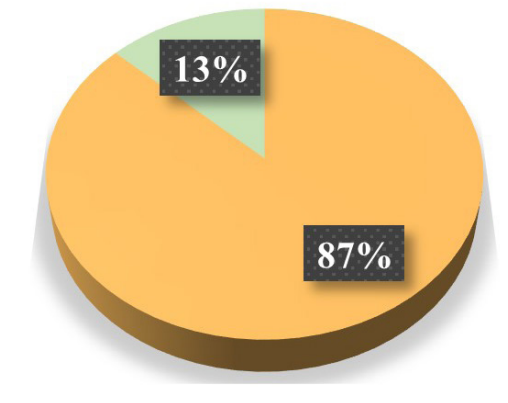

FIGURA 11. Resultados del criterio de calificación "significancia"

FUENTE: elaboración propia (2020).

En la Figura 11 se puede observar que la mayoría de los impactos identificados para el escenario con bonos de carbono corresponden a la calificación significativo. Esta clasificación permite determinar qué acciones, aspectos e impactos ambientales no se encuentran reglamentados, es decir que no cuentan o no cumplen con la normatividad. En este caso, como se mencionó, la captura de carbono está enfocada en la biomasa arbórea, para lo cual se han diseñado metodologías para su medición y la zonificación de áreas aptas para tal fin, pero esto deja algunos vacíos para el desarrollo de proyectos de captura de carbono en el suelo bajo el esquema de pago por servicio ambiental, razón por la 
cual algunos impactos positivos y negativos son calificados cualitativamente como significativos.

En los impactos calificados como no significativos se observó que los componentes del medio abiótico son los que abarcan mayoritariamente esta clasificación, ya que están relacionados con el componente de suelo. Estos son: el mejoramiento de la capacidad de resiliencia, cambio en la calidad y la fertilidad, y la disminución de su degradación, en donde el aumento de la materia orgánica en el suelo, debido a que la captura de carbono tiene directamente un impacto positivo en el recurso, y bajo la política para la gestión sostenible del suelo, los esquemas de ordenamiento territorial de los municipios que hacen parte del ecosistema y el alinderamiento del páramo La Cortadera como área protegida, se reglamenta el uso del suelo, lo cual contribuye a la recuperación del ecosistema y de la calidad del recurso mencionado.

\section{Conclusiones y recomendaciones}

- Para el escenario con bonos de carbono, la evaluación ambiental mostró que en general la prestación del servicio ambiental es una buena estrategia para la recuperación del ecosistema. Sin embargo, inicialmente se debe dar prioridad a los planes de manejo de los impactos negativos, de alta importancia y significativos debido a que los páramos son simbióticos de múltiples atributos biofísicos y la prestación del servicio ambiental de captura de carbono puede verse afectada por su alta sensibilidad al cambio climático.

- $\quad$ Si bien en el escenario con bonos de carbono se presentan impactos negativos, estos son principalmente asociados a la estructuración de las entidades con jurisdicción en el páramo La Cortadera en lo relacionado con el trabajo conjunto con las organizaciones comunitarias y la definición de objetivos para la conservación y la preservación del ecosistema. Adicionalmente, los impactos negativos requieren la unificación de esfuerzos entre entidades con interés en el ecosistema y prestar especial atención en la priorización del manejo de las acciones que generan impactos negativos, con el fin de evitar su potencialización y disminuir las dificultades en el proceso de certificación de captura de carbono del suelo para su valoración económica, ambiental y jurídica.

- En el escenario con bonos de carbono es de gran importancia considerar la susceptibilidad del ecosistema ante la presión antrópica de los recursos naturales, ya que en el desarrollo e implementación de proyectos de captura se pueden ver alterados los resultados esperados en cuando a la aptitud del suelo en el área de estudio. Es importante conocer cómo se comporta el ecosistema con el fin de relacionar las variables y certificar la captura de carbono en el suelo del páramo.

- El desarrollo de estrategias para la vinculación del área protegida del páramo La Cortadera a un esquema de pago por servicios ambientales permitirá conservar la cobertura vegetal natural, fortalecer la aplicación de instrumentos ambientales de comando y control y reducir el impacto por disturbios naturales.

\section{Referencias}

Africano, K., Cely, G., \& Serrano, P. (2016). Potencial de captura de $\mathrm{CO}_{2}$ asociado al componente edáfico en páramos Guantiva-La Rusia, departamento de Boyacá, Colombia. Perspectiva Geográfica, 21(1), 91-110. https://doi.org/10.19053/01233769.4572

Álvarez, J. \& Barreto, P. (2016). Disyuntivas ambientales y políticas de los campesinos paperos del páramo de Cortadera en Boyacá - Colombia. Revista Psicología Política, 16(37), 321-334. 
Amar, A. (2009). Diagnóstico, evaluación y estado actual de las especies de páramo que hacen parte del páramo de Cortadera en los municipios de Tuta, Pesca, Toca y Siachoque departamento de Boyacá. Corporación Autónoma Regional de Boyacá - Asociación para el mejoramiento del Medio Ambiente, de los Recursos Naturales y para la Activación del Desarrollo Social - Comunitario, Subdirección de Planeación y Sistemas.

Andrade, G. (2013). La alta montaña del páramo y la incierta gestión de los servicios ecosistémicos de la alta montaña en escenarios de cambio ambiental. En J. Cortés-Duque \& C. Sarmiento (eds.), Visión socioecosistémica de los páramos y la alta montaña colombiana: memorias del proceso de definición de criterios para la delimitación de páramos (pp. 127-140). Instituto de Investigación de Recursos Biológicos Alexander von Humboldt.

Autoridad Nacional de Licencias Ambientales (ANLA) (2018). Metodología general para la elaboración y presentación de estudios ambientales. http://portal.anla.gov.co/sites/ default/files/comunicaciones/permisos/metodologia_estudios_ambientales_2018.pdf

Bocarejo, D., Cairo, C., Ojeda, D., Montenegro, I., Murcia, F., \& Rojas Arias, F. (2014). Caracterización socioeconómica y cultural del complejo de páramos Tota-Bïagual-Mamapacha en jurisdicción de Corpoboyacá con énfasis en caracterización de actores, análisis de redes y de servicios ecosistémicos. Instituto de Investigación de Recursos Biológicos Alexander von Humboldt; Fundación Erigaie.

Cárdenas, F. (2007). Antropología en perspectiva ambiental. Universidad de la Sabana.

Conesa, V. (1993). Guía metodológica para la evaluación del impacto ambiental. ( $2^{\mathrm{a}}$ ed.). Mundi-Prensa.

Corporación Autónoma Regional de Boyacá (Corpoboyacá) (2015). Acuerdo 024 de 2015. Por el cual se declara y alindera el Parque Natural Regional Cortadera, ubicado en los municipios de Siachoque, Toca, Pesca, Rondón y Tuta, jurisdicción de la Corporación Autónoma Regional de Boyacá - Corpoboyacá.

Gobernación de Boyacá (2013). Páramos en el departamento de Boyacá. http://www.boyaca.gov.co/

Greenpeace (2013). Páramos en peligro. El caso de la minería de carbón en Pisba. www.greenpeace.org/colombia
Hernández, D. \& Lizarazo, M. (2015). Bacterias heterótrofas oligotróficas en zonas conservadas e intervenidas del páramo de La Cortadera, Boyacá, Colombia. Revista U.D.C.A Actualidad \& Divulgación Científica, 18(2), 475-483. https://doi.org/10.31910/rudca.v18. $\mathrm{n} 2.2015 .178$

Instituto de Investigación de Recursos Biológicos Alexander von Humboldt (2007). Atlas de páramos de Colombia. http://www.humboldt.org.co/es / estado-de-los-recursos-naturales/item/299-atlas-de-paramos-de-colombia

Márquez, G. (2014). Ecosistemas estratégicos para la sociedad: bases conceptuales y metodológicas. Universidad Nacional.

Maza, C. (2007). Evaluación de impactos ambientales. En Manejo y conservación de recursos forestales (pp. 579-609). Editorial Universitaria.

Ministerio del Medio Ambiente (2002). Programa para el Manejo Sostenible y Restauración de Ecosistemas de Alta Montaña colombiana. Ministerio del Medio Ambiente.

Pérez, F., Cely, G., \& Serrano, P. (2018). Cuantificación de la captura de carbono y análisis de las propiedades del suelo en coberturas naturales y una plantación de pino en el páramo de Rabanal, Colombia. Cuadernos de Geografia: Revista Colombiana de Geografia, 28(1), 121133.

Rivera, D. \& Rodríguez, C. (2011). Guía divulgativa de criterios para la delimitación de páramos en Colombia. Instituto de Investigación de Recursos Biológicos Alexander von Humboldt. http://humboldt.org.co/es/estado-delos-recursos-naturales/item/88-guia-divulgativade-criterios-para-la-delimitacion-de-paramos-decolombia

Secretaría Distrital de Ambiente (2013). Instructivo: diligenciamiento de la matriz de identificación de aspectos $y$ valoración de impactos ambientales. https://www.ambientebogota.gov.co/documents/10184/564058/ Instructivo+para+el+diligenciamiento + de $+\mathrm{la}+$ matriz+de+Identificaci $\% \mathrm{C} 3 \% \mathrm{~B} 3 \mathrm{n}+\mathrm{de}+$ aspectos $+\mathrm{y}+$ valoraci $\% \mathrm{C} 3 \% \mathrm{~B} 3 \mathrm{n}+\mathrm{de}+$ impactos + ambientales.pdf/ e5f7edbd-f5d8-4008-8bda-fb9328d8b98b

Wood, C. (2003). Environmental Impact Assessment in Victoria, a comparative review. Prentice Hall. 